\title{
Sex differences in the prevalence and determinants of HPV-related external genital lesions in young adults: a national cross-sectional survey in Brazil
}

Juliana Comerlato ${ }^{1,2}$, Natália Luiza Kops ${ }^{3}$, Marina Bessel ${ }^{3}$, Jaqueline Driemeyer Horvath³ ${ }^{3}$ Bruna Vieira Fernandes ${ }^{1,2}$, Luisa Lina Villa ${ }^{4}$, Flavia Moreno Alves de Souza ${ }^{5}$, Gerson Fernando Mendes Pereira ${ }^{5}$ and Eliana Márcia Wendland ${ }^{1,2^{*}}$

\begin{abstract}
Background: External genital lesions (EGL) are the most common sexually transmitted infections (STIS). We aimed to evaluate the prevalence, determinants and sex differences in EGL among young adults from Brazil.

Methods: Overall, 7694 participants (aged 16 to 25 years) underwent an interview, genital examination and sampling for HPV genotyping.

Results: The prevalence of EGL was 4.08\% (234) and is more frequent in men (5.72\%) than women (2.31\%) $(p<0.001)$. Genital lesions were significantly associated with male sex, infection by high-risk and multiple HPV types, having more than two sexual partners in the last year, smoking status and the presence of other STI. While alcohol use was associated with a higher prevalence of EGL in women, same-sex sexual relationship increase the prevalence in men. In the EGL group, 67.79\% ( $p=0.032)$ were positive for HPV infection and the types HPV6 and HPV11 were the most prevalent ones.

Conclusion: The prevalence of EGL in young adults was consistently high, and most cases were associated with genital HPV infection and STIs. Although men have a higher prevalence, both sexes share most genital lesion determinants. The promotion of sexual education and vaccination especially focus in young men, who are usually outside the targets of primary health care programmes, can prevent EGL in Brazilian young adults.
\end{abstract}

Keywords: Human papillomavirus, Genital warts, HPV, Epidemiology, Prevalence in young adults

\section{Background}

Human papillomavirus (HPV) lesions of the external genital region, which are commonly identified as genital warts (GW), are the most common outcome of HPV infection, followed by low-grade squamous intraepithelial lesions and cervical, penile, anal and head and neck

\footnotetext{
* Correspondence: elianawend@gmail.com

'Hospital Moinhos de Vento, PROADI - SUS, Ramiro Barcelos, 910, Porto Alegre, RS 90035-004, Brazil

${ }^{2}$ Federal University of Health Sciences of Porto Alegre, Graduate Programs in Health Sciences and Pediatrics, Porto Alegre, Brazil

Full list of author information is available at the end of the article
}

cancers $[1,2]$. The lifetime probability of acquiring HPV was estimated to be $84.6 \%$ among women and $91.3 \%$ among men [3]. Among all HPV types, HPV6 and HPV11 are the most commonly detected types responsible for external genital lesions (EGL). HPV6 and HPV11 belong to the low-risk HPV (LR-HPV) group and are known for their low association with carcinoma development [4]. Additionally, the costs associated with the diagnosis and treatment of HPV lesions reported in the international literature are substantial [5-7]. In Brazil, the healthcare costs for genital warts treatment

(c) The Author(s). 2020 Open Access This article is licensed under a Creative Commons Attribution 4.0 International License, which permits use, sharing, adaptation, distribution and reproduction in any medium or format, as long as you give appropriate credit to the original author(s) and the source, provide a link to the Creative Commons licence, and indicate if changes were made. The images or other third party material in this article are included in the article's Creative Commons licence, unless indicated otherwise in a credit line to the material. If material is not included in the article's Creative Commons licence and your intended use is not permitted by statutory regulation or exceeds the permitted use, you will need to obtain permission directly from the copyright holder. To view a copy of this licence, visit http://creativecommons.org/licenses/by/4.0/. The Creative Commons Public Domain Dedication waiver (http://creativecommons.org/publicdomain/zero/1.0/) applies to the data made available in this article, unless otherwise stated in a credit line to the data. 
among the sexually active population is estimated to range from $\$ 34$ to $\$ 40$ million over the next five years [8].

The presence of EGL is commonly associated with the presence of HPV genital infection; however, the diagnosis of HPV is often difficult, and the treatment is usually performed in a syndromic approach [9]. Additionally, 90\% of individuals with genital HPV infection do not develop symptoms as numerous individual factors are associated with different outcomes [4]. Several characteristics, such as sex, race/skin colour, age at first intercourse, smoking status, the presence of other sexually transmitted infections (STI), multiple HPV infections and lifetime number of sexual partners, have been linked to the presence of genital lesions [10].

HPV immunization provides direct protection against HPV types included in the vaccine. Currently, the national HPV vaccination programme in Brazil provides the quadrivalent HPV vaccine (HPV 6/11/16/18) for girls and boys between 9 and 14 years old. Although the types commonly associated with genital lesions are included in the quadrivalent vaccine, multiple infection types can cause an increase in genital lesion incidence; therefore, it is important to understand the type distribution in the Brazilian population [11, 12].

To date, few studies investigating the association among EGL, the presence of genital HPV infection and genotype in Latin America have been conducted [13]. The currently published studies have been restricted to male individuals and include limited nationwide sampling [13-16].

Considering that data regarding the prevalence of EGL and associated factors are scarce in Brazil, the purpose of this study is to evaluate the prevalence, determinants and sex differences in EGL among sexually active young adults from Brazil.

\section{Methods}

We used data from the POP-Brazil study, a crosssectional, multicentric, nationwide study designed to evaluate HPV infection and its associated factors among sexually active women and men aged between 16 and 25 years in all geographic regions of Brazil $[17,18]$, to evaluate the prevalence of external genital lesions. In total, 7694 samples from non-vaccinated individuals from 119 primary care units were collected between September 2016 and November 2017 by trained primary health care professionals. The exclusion criteria were as follows: pregnancy, previous hysterectomy or trachelectomy, and a history of cervical intraepithelial neoplasia grade 2 or higher.

All individuals consenting to participate were invited to answer a standardized questionnaire based on validated instruments to provide information regarding sociodemographic factors and prior and current sexual health and behaviours. The presence of STIs (HIV, syphilis, gonorrhoea and/or herpes) was self-reported. Additionally, the participants were invited to undergo a rapid HIV and syphilis test. During the sampling, the presence of any lesion in the external genital region was investigated and reported by the health care professional. Genital HPV infection was assessed in cervical samples collected with a digene ${ }^{\circ} \mathrm{HC} 2$ DNA Collection Device (Qiagen, Hulsterweg, the Netherlands) and by supervised penile auto-collection using a digene ${ }^{\circ}$ Female Swab Specimen Collection Kit (Qiagen). Genital (cervical or penile) samples were analysed to detect HPV infection by DNA extraction with a MagNA Pure LC 2.0 Instrument and DNA Isolation Kit III (Roche Life Science, Basel, Switzerland); the HPV detection and genotyping were conducted with a Linear Array ${ }^{\circ}$ HPV Genotyping Test (LA HPV) (Roche Life Science, Basel, Switzerland). The LA HPV is based on PCR amplification [450 base pair (bp) fragment of the polymorphic region of the L1 gene of HPV], followed by specific hybridization and colorimetric detection according to the manufacturer's instructions. The test can detect thirteen types of high-risk HPV (HR-HPV) $(16,18,31,33,35,39,45,51,52,56,58$, 59 and 68$)$ and twenty-four types of LR-HPV $(6,11,26$, $40,42,53,54,55,61,62,64,66,67,69,70,71,72,73$, 81, 82, 82v [IS39], 83, 84, and 89 [CP6108]). The test include the amplification of the human $\beta$-globin $(268 \mathrm{bp}$ fragment) gene was used as an internal control for sample adequacy. An AutoBlot instrument (MedTec Biolab, Hillsborough, NC, USA) was used to automate the hybridization and wash steps. The LA HPV test probes against HPV types $33,35,52$, and 58 are cross-reactive; therefore, if the tests using these probes were positive, we performed additional analyses using a specific realtime PCR assay as previously described [19]. The samples were stored and transported to the laboratory according to the recommendations by the protocol manufacturer. All samples were processed in the same laboratory.

The data were analysed using SAS software (Statistical Analysis System, SAS Institute Inc., Cary, NC, USA) version 9.4. The descriptive data are presented as frequencies (\%), means and confidence interval (CI). ANOVA, Chi-squared or Student's t-test were used to compare the characteristics between the groups. To compare proportions, a chi-square test was used. Normal distribution was determined through the Anderson-Darling test, and Student's t-test was applied to compare the continuous variables when appropriate. A Poisson regression with robust variance was conducted to examine the factors associated with EGL. A theoretical framework was structured as follows with the associated variables differentiated in hierarchical blocks: HPV presence (Model 1); model $1+$ age (Model 2); model $2+$ alcohol consumption 
(Model 3); model 3 + condom use, having more than 2 partners in the prior year, and STI presence (Model 4) [20]. To adjust for the distribution of the sample to the study population, we weighted the measures by the population size in each capital and sex. Therefore, all results are reported as weighted, and statistical significance is defined as $p<0.05$.

\section{Results}

Of the 7694 participants included in the study, the prevalence of EGL was 4.08\% (95\% CI: 3.22-4.94), and significant differences in prevalence were observed according to sex. Men have a higher prevalence of EGL (5.72\%) than women $(2.31 \%, p<0.001)$.

The group of participants with lesions had a higher frequency of STIs $(42.97 \%)$ than the groups of participants without lesions $(12.78 \% ; p<0.001)$. The EGL group were also associated with current smoking (24.41\%), alcohol consumption (82.68\%), having two or more sexual partners in the prior year $(50.68 \%)$ and having a same-sex relationship (14.87\%). A higher prevalence of lesions was observed in the Southeast region $(30.00 \%, p<0.001)$. Significant differences were not observed in the variable "age at first sexual intercourse" between the groups [15.38 mean age in years of individuals with lesions (95\% CI: $15.09-15.67$ ) versus 15.35 without lesions (95\% CI: 15.30-15.40)]. Age, race/skin colour, relationship status, and condom use were not associated with the presence of EGL (Table 1).

The characteristics associated with the presence of EGL varied according to sex. Men had more samesex sexual experiences, a higher number of partners in the prior year and more STIs than the women (Fig. 1). The prevalence of lesion also differed significantly by geographic region: the highest positivity in women was reported in Northeast (37.73\%), and that among the men was observed in the Midwest (31.71\%) (Fig. 2).

Of the 234 individuals with lesions, 195 provided valid samples for analysis (human $\beta$-globin positive); of these individuals, $67.79 \%$ (132) were positive for HPV DNA compared to $53.03 \%$ positivity among those without lesions $(p=0.032)$. The frequency of infection by HR-HPV (50.20\%) and multiple genotype infection (43.71\%) were higher among the people with lesions than among those without lesions (HR-HPV; 34.54\%, $p=0.012$ and multiple infection; $30.49 \%, p=0.025)$. There was no statistically significant difference in LR-HPV infection between the groups $(52.37 \%$ with lesions versus $40.08 \%$ without lesions, $p=0.057$ ) (Fig. 3).

The most frequently identified HPV genotypes in the participants with lesions were HPV16 (12.55\%), HPV6 (9.22\%), HPV11 (8.82\%), HPV62 (8.67\%), HPV58
Table 1 Sociodemographic characteristics and sexual behaviour associated with external genital lesions (EGL) in Brazilian young adults

\begin{tabular}{|c|c|c|c|}
\hline & EGL group & Without lesions & $P$-Value \\
\hline Characteristics & $\%$ & $\%$ & \\
\hline Age & & & 0.091 \\
\hline $16-17$ & 4.56 & 11.11 & \\
\hline $18-19$ & 18.47 & 21.76 & \\
\hline $20-21$ & 20.30 & 22.27 & \\
\hline $22-23$ & 25.10 & 22.34 & \\
\hline $24-25$ & 31.57 & 22.51 & \\
\hline Race/skin colour & & & 0.494 \\
\hline White & 24.02 & 23.67 & \\
\hline Black & 11.98 & 17.14 & \\
\hline Brown & 62.08 & 56.64 & \\
\hline Other & 1.92 & 2.55 & \\
\hline Relationship status & & & 0.137 \\
\hline Single or without partner & 33.13 & 24.00 & \\
\hline Dating or flirting & 39.41 & 41.13 & \\
\hline Married or living together & 27.46 & 34.87 & \\
\hline \multicolumn{2}{|c|}{ Number of sexual partners in the last year } & & $<0.005$ \\
\hline$<2$ & 49.32 & 67.78 & \\
\hline$\geq 2$ & 50.68 & 32.22 & \\
\hline Smoking status & & & 0.039 \\
\hline Non-smoker & 53.23 & 64.88 & \\
\hline Smoker & 24.41 & 15.18 & \\
\hline Ex-smoker & 22.36 & 19.93 & \\
\hline Region of Brazil & & & $<0.001$ \\
\hline Midwest & 27.04 & 11.68 & \\
\hline Northeast & 22.26 & 28.51 & \\
\hline North & 12.26 & 12.57 & \\
\hline Southeast & 30.00 & 40.66 & \\
\hline South & 8.44 & 6.58 & \\
\hline Alcohol consumption & 82.68 & 71.75 & 0.048 \\
\hline Condom use & 60.44 & 50.06 & 0.069 \\
\hline $\begin{array}{l}\text { History of same-sex sexual } \\
\text { experience }\end{array}$ & 14.87 & 7.40 & 0.041 \\
\hline Presence of STI & 42.97 & 12.78 & $<0.001$ \\
\hline Syphilis infection & 4.54 & 3.86 & 0.708 \\
\hline
\end{tabular}

STI sexually transmitted infections

(8.36\%), HPV52 (8.19\%) and HPV51 (8.01\%). By comparing the groups with and without lesions, HPV11 $(8.82 \%$ versus $1.09 \%$ without lesions; $p<0.001$ ) and HPV6 $(9.22 \%$ versus $5.36 \% ; p=0.051)$ were significantly higher in the group with lesions. There was no difference in the prevalence of specific HPV types according to sex (data not shown). 


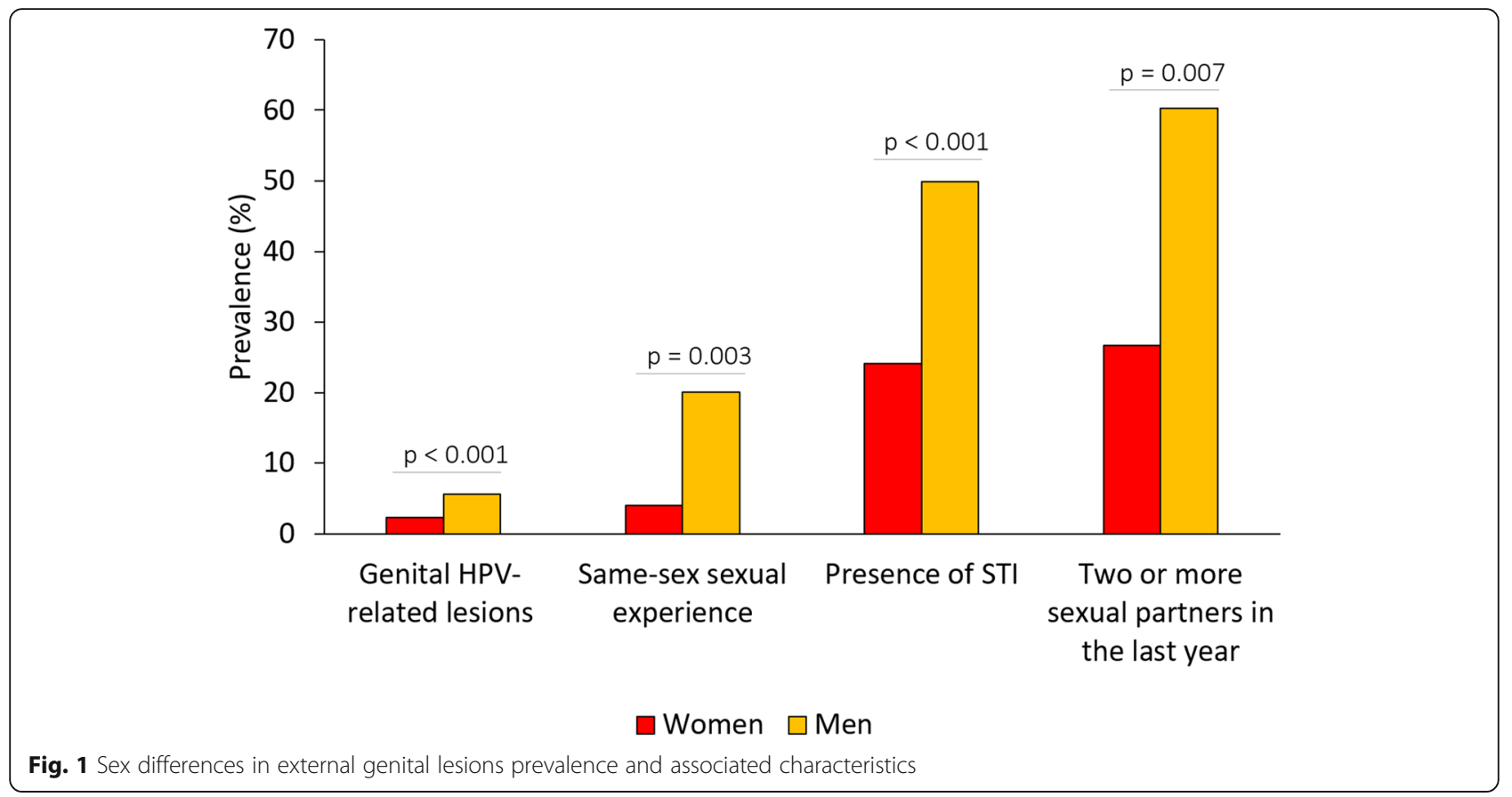

When we stratified the multivariate analysis by sex, HPV infection was associated with EGL only in the women [PR 1.74 (95\% CI: 1.03-2.96)]. However, HPV lost significance after incorporating STIs into the model, and no interaction was observed between HPV and STI. Alcohol consumption was independently associated with the presence of lesions in the women [PR 1.91 (95\% CI: 1.09-3.33)]. HPV was not associated with lesions in men, and those with STI were 3.13 times (95\% CI: $1.57-$ 6.24) more likely to have genital lesions than nonexposed subjects (Table 2).

\section{Discussion}

We studied a large Brazilian young adult population aged 16 to 25 years and found that the prevalence of external genital lesions was $4.08 \%$. This is the first

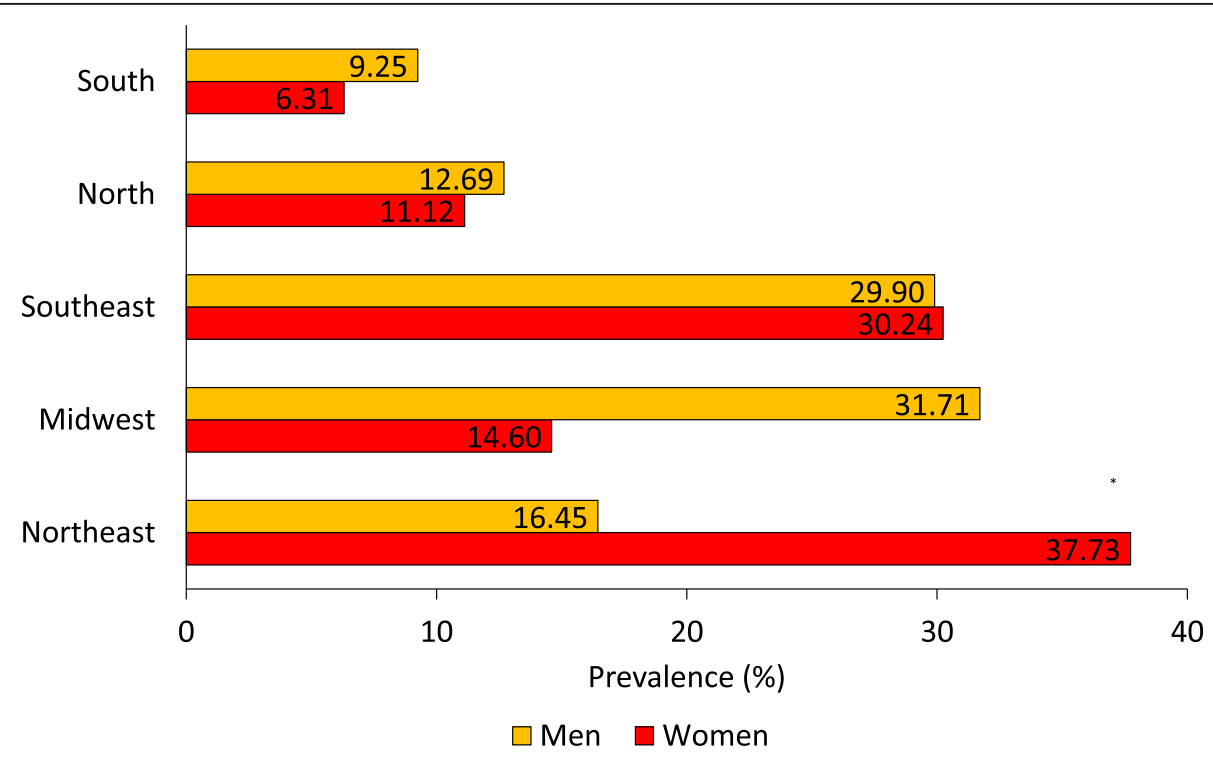

Fig. 2 Sex distribution of external genital lesions by Brazilian geographical region. ( ${ }^{*} P$ value $=0.032$ ) 


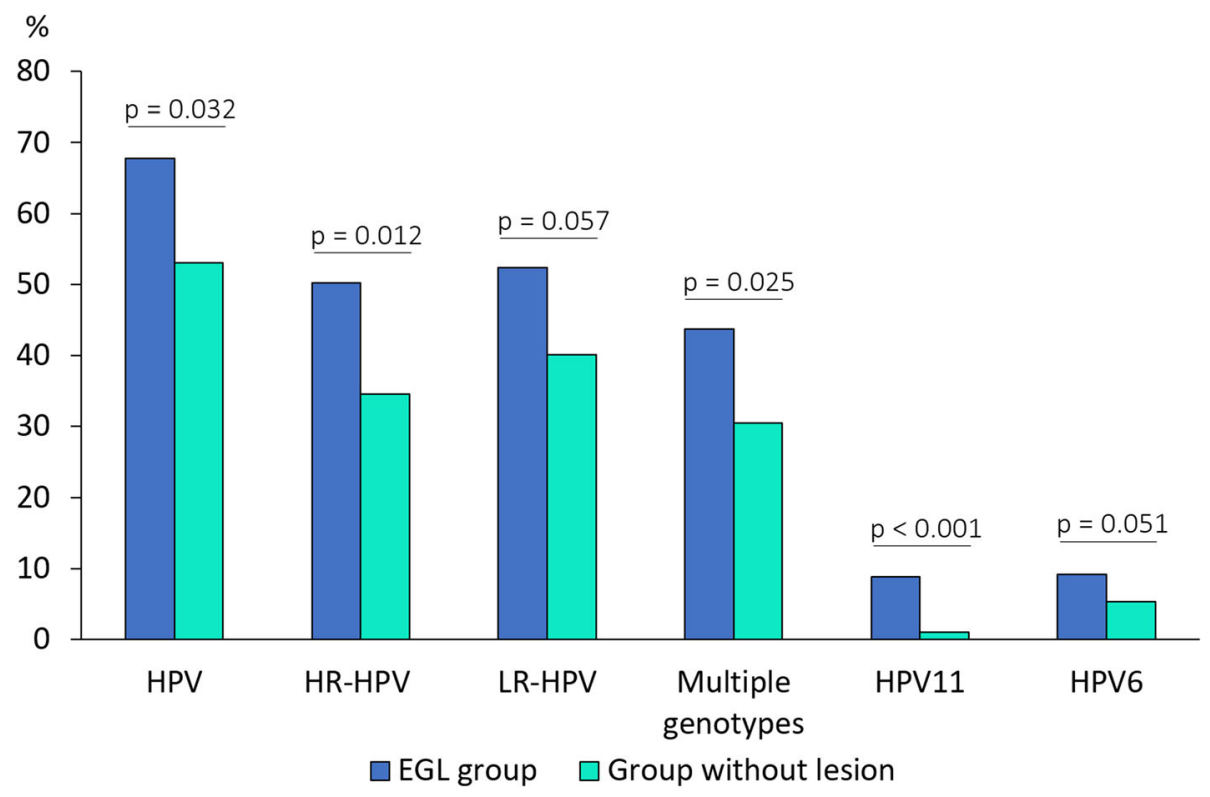

Fig. 3 HPV DNA prevalence in participants with and without external genital lesions (EGL)

nationwide study to assess the prevalence of EGL and its differences by sex in all five Brazilian geographical regions. In our study, the prevalence of lesions was higher in men $(5.72 \%)$ than women $(2.31 \%)$ and was associated with HPV infection only when STIs were not considered.
The viruses commonly associated with lesions, HPV6 and HPV11, [21] were also most frequently associated with EGL in this study.

The prevalence rates found are high, similar to that reported in Mexico (5.10\%), Hungary (4.03\%) and the USA

Table 2 Prevalence ratios of determinants of external genital lesions according to sex. POP-Brazil Study, 2016-2017

\begin{tabular}{|c|c|c|c|c|}
\hline & \multicolumn{4}{|c|}{ Prevalence Ratio (95\% Cl) } \\
\hline & Model 1 & Model 2 & Model 3 & Model 4 \\
\hline \multicolumn{5}{|l|}{ Women } \\
\hline Presence of HPV & $1.87(1.11-3.16)^{*}$ & $1.87(1.10-3.19)^{*}$ & $1.74(1.03-2.96)^{*}$ & $1.35(0.78-2.33)$ \\
\hline \multicolumn{5}{|l|}{ Age } \\
\hline$\leq 20$ years & & 1 & 1 & 1 \\
\hline$>20$ years & & $1.01(0.61-1.67)$ & $1.00(0.61-1.65)$ & $0.86(0.52-1.43)$ \\
\hline Alcohol consumption & & & $2.17(1.30-3.62)^{*}$ & $1.91(1.09-3.33)^{*}$ \\
\hline Condom use & & & & $0.77(0.46-1.29)$ \\
\hline More than 2 partners in the last year & & & & $1.18(0.67-2.06)$ \\
\hline Presence of STI & & & & $2.03(1.10-3.73)^{*}$ \\
\hline \multicolumn{5}{|l|}{ Men } \\
\hline Presence of HPV & $1.87(0.87-4.03)$ & $1.80(0.82-3.95)$ & $1.84(0.83-4.07)$ & $1.99(0.82-4.83)$ \\
\hline \multicolumn{5}{|l|}{ Age } \\
\hline$\leq 20$ years & & 1 & 1 & 1 \\
\hline$>20$ years & & $1.74(0.84-3.59)$ & $1.71(0.82-3.56)$ & $1.22(0.56-2.64)$ \\
\hline Alcohol consumption & & & $1.12(0.42-2.98)$ & $2.53(0.81-7.94)$ \\
\hline Condom use & & & & $0.46(0.21-1.01)$ \\
\hline More than 2 partners in the last year & & & & $1.69(0.75-3.82)$ \\
\hline Presence of STI infection & & & & $3.13(1.57-6.24)^{*}$ \\
\hline
\end{tabular}

HPV Human Papillomavirus, STI Sexually Transmitted Infection, Cl Confidence Interval, Model 1 presence of HPV, Model 2 model 1 and age, Model 3 model 2 and alcohol consumption, Model 4 model 3 and condom use, more than two partners in the last year, and presence of STI. * $p<0.05$ 
(4.10\%), and much higher than that in most countries, such as Italy (0.05\%), Canada (1.10\%) [22] and Vietnam $(0.20 \%)$; the peak incidence in the young population occurred between the ages of 18 and 29 years [1, 23].

Data regarding the prevalence of genital lesions in men from low/middle income countries are scarce [1,24-26]. These studies used different epidemiological and analytical methodologies, which could explain the differences in prevalence: $5.25 \%$ in Peru [1], $1.22 \%$ in India [24] and $1.99 \%$ in Mexico [25]. The incidence reported in Mexico was $42 \%$, and that in Brazil was $31.9 \%$ over a period of four years [26]. The higher prevalence of genital lesions in men could be explained by the higher frequency of STIs in this population [17]. A previous study performed in the women from a region on the North of Brazil associated HPV with other STIs, suggesting that individuals with HPV infection are at an increased risk of having another STI [27]. Similar results have already been reported in Seoul, Korea and Trieste, Italy [28, 29]. Additionally, STIs other than HPV or HPV co-infection, could also lead to EGL. The self-reported STIs by the participants could also include some HPV lesions, leading to a higher association with EGL.

We found a statistically significant association between alcohol consumption and the presence of EGL. An association between alcohol and HPV prevalence has been previously reported. Alcohol intake was associated with a higher positivity of HPV infection and HR-HPV types in men [30]. In women, alcohol intake was associated with a higher HPV viral load, a higher risk of cervical intraepithelial neoplasia grade 1 (CIN1), and HPV infection in female sex workers [31, 32]. The increase in genital lesions associated with alcohol could be due to an increase in the presence of HPV infection or a greater susceptibility to the development of EGL.

The rate of HPV infection in the participants with EGL $(67.79 \%)$ was similar to that reported in other studies (72.3\% in Brazil, $61.3 \%$ in the USA, and $61.9 \%$ in Mexico HIM Study), but lower than the results obtained in Thailand (88.3\%), Turkey (75.8\%), Colombia (88.9\%), China (97.0\%) and Ireland (78\%) [13, 14, 33-36]. The discrepancy between these results could be due to differences in the sampling techniques or methods, misdiagnoses or true differences among the populations. The LA HPV test, which is the technique chosen in this study, presents a high sensitivity (96\%) and specificity (99\%), and it is unlikely that variations in the genotyping test could explain the lack of positivity in $32 \%$ of individuals with lesions; however, we cannot exclude the possibility of the existence of HPV types undetectable by this technique or those individuals with low viral loads [37]. Also, a clinical diagnosis could be misleading as EGL caused by HPV clinically resemble other common genital lesions, such as those caused by molluscum contagiosum, keratosis, etc. To exclude other STIs, we asked the participants whether they have ever had a herpes virus infection and performed a syphilis rapid test. None of the participants reported genital herpes infection; however, $6.49 \%$ of the participants who presented lesions and were negative for HPV infection were positive for syphilis (data not shown).

Among the participants with genital lesions positively genotyped to HPV, 52.37\% were positive for LR-HPV, and $50.20 \%$ were positive for HR-HPV. Although our study population had a much lower rate of HPV6 and/or HPV11 $(24.55 \%)$ than other populations, [38, 39] we found a high frequency of HR-HPV types not commonly associated with EGL. Additionally, high rates of multiple infections were observed; this result is consistent with the data recently published by Hasanzadeh et al. (2019), who demonstrated that patients with multiple infections by LR- and HR-HPV types and those with a single infection by HR-HPV had an increased risk of developing GW [OR: 2.81; (95\% CI: PR 1.21-6.55) and OR: 2.33; (95\% CI: PR 1.03-5.27), respectively] [12].

Our study has both strengths and limitations. Because of the potential to report socially desirable responses or lack of knowledge, self-reported data have inherent biases that could lead to the underreporting of alcohol consumption or overreporting of STI. Additionally, we do not have enough data to address deeply some specific population as men and women who have same sex relationship. We also performed HPV testing of all the genital region in the men - including areas without lesions while in the women, the cervix and external areas with lesions were tested. This strategy allowed for the identification of all HPV types present in the genitalia in addition to the area with EGL. This strategy could lead to an increase in other HPV genotypes not related to the lesion in the men and a decrease the types associated with lesions in the women. Additionally, the diagnosis of HPV-related lesions was performed only through visual inspection, leading to misclassification bias. Although we did not perform histological testing to confirm the clinical diagnosis, Hernandez-Suarez et al. concluded that only $19 \%$ of clinically diagnosed HPV-related lesion cases were not confirmed by microscopy [13].

Some specific populations as men who have sex with men and the impact of vaccination in this population compared to heterosexual men regarding the prevalence of EGL could not be addressed in this study and deserves further investigation as well as the impact of vaccination in EGL lesion in the Brazilian population.

\section{Conclusions}

Our data provide important information regarding the prevalence of external genital lesions and their determinants while also exploring the differences between the sexes. The results can be used for the development of 
public health strategies to focus on the affected groups, such as young men, who are usually outside the targets of primary health care programmes. Furthermore, these data reinforce the importance of sexually transmitted infections prevention and the need to include boys in HPV vaccination programmes.

\section{Abbreviations}

Cl: Confidence interval; EGL: External genital lesions; GW: Genital warts; HPV: Human papillomavirus; HR-HPV: High-risk HPV; LA HPV: Linear Array ${ }^{\circledast}$ HPV Genotyping Test; LR-HPV: Low-risk HPV; SAS: Statistical Analysis System; STIs: Sexually transmitted infections

\section{Acknowledgements}

We would like to acknowledge all healthcare professionals who contributed to the data acquisition process during the first stage of this research (20152017). We are especially grateful to Juliana Caierão, Gláucia Hohenberger, Bárbara Pereira de Mello (FMUSP) and Thais Machado Baptista.

\section{Authors' contributions}

The author contributions are as follows: JC drafted the manuscript; NLK acquired and interpreted the data and drafted the manuscript; JDCH and EMW designed the study, interpreted the data and reviewed the final manuscript; BVF and LLV acquired the data and reviewed the final manuscript; FMAS and GFMP interpreted the data and reviewed the final manuscript; and $\mathrm{MB}$ analysed and acquired the data. All authors have read and approved the manuscript. EMW had full access to all data in the study and is responsible for the integrity of the data and the accuracy of the data analysis.

\section{Funding}

This work was financed by Hospital Moinhos de Vento through the Program for Supporting the Institutional Development of the Public Health System (PROADI-SUS) and supported by the Brazilian Ministry of Health. The Federal University of Health Sciences of Porto Alegre contributed to the development and application of the laboratorial methodologies.

\section{Availability of data and materials}

The datasets used and/or analysed during the current study are available from the corresponding author on reasonable request.

\section{Ethics approval and consent to participate}

This research was approved by the Ethics Committee on Human Research of the Moinhos de Vento Hospital research board (Approval No. 1607032) and the committees of all recruitment sites in Brazil. All participants provided written consent after being informed about the content of the study. Our study was performed in accordance with the Declaration of Helsinki.

\section{Consent for publication}

Not applicable.

\section{Competing interests}

Luisa L. Villa is a consultant and speaker for HPV vaccines at Merck, Sharp \& Dohme and a consultant for BD, Roche and Qiagen regarding HPV tests. All other authors have no conflicts of interest to declare.

\section{Author details}

${ }^{1}$ Hospital Moinhos de Vento, PROADI - SUS, Ramiro Barcelos, 910, Porto Alegre, RS 90035-004, Brazil. 'Federal University of Health Sciences of Porto Alegre, Graduate Programs in Health Sciences and Pediatrics, Porto Alegre, Brazil. ${ }^{3}$ Hospital Moinhos de Vento, Porto Alegre, Brazil. ${ }^{4}$ Faculdade de Medicina, University of São Paulo and Instituto do Câncer do Estado de São Paulo (ICESP), São Paulo, Brazil. ${ }^{5}$ Department of Chronic Conditions and Sexually Transmitted Infections, Ministry of Health, Brasília, Brazil.
Received: 14 January 2020 Accepted: 26 August 2020

Published online: 18 September 2020

\section{References}

1. García PJ, Carcamo CP, Valderrama M, La Rosa S, James C, Gutiérrez R, et al. Burden of genital warts in Peru: an observational study. Int J STD AIDS. 2019:30(3):264-74

2. Forman D, de Martel C, Lacey CJ, Soerjomataram I, Lortet-Tieulent J, Bruni L, et al. Global burden of human papillomavirus and related diseases. Vaccine. 2012;30:F12-23.

3. Chesson HW, Dunne EF, Hariri S, Markowitz LE. The estimated lifetime probability of acquiring human papillomavirus in the United States. Sex Transm Dis. 2014:41(11):660-4.

4. Leslie SW, Gossman WG. Genital warts. In: StatPearls [internet]. Treasure Island. FL: StatPearls Publishing; 2020.

5. Dahlstrom KR, Fu S, Chan W, Shelal Z, Ramondetta LM, Lairson DR. Medical care costs associated with genital warts for commercially insured US patients. PharmacoEconomics. 2018;36(11):1355-65.

6. Östensson E, Fröberg M, Leval A, Hellström A-C, Bäcklund M, Zethraeus N, et al. Cost of preventing, managing, and treating human papillomavirus (HPV)-related diseases in Sweden before the introduction of Quadrivalent HPV vaccination. PLoS One. 2015;10(9):e0139062.

7. Gianino MM, Delmonte S, Lovato E, Martinese M, Rondoletti S, Bernengo $M G$, et al. A retrospective analysis of the costs and management of genital warts in Italy. BMC Infect Dis. 2013;13:470.

8. CONITEC C. Dois medicamentos para tratamento de HPV são incorporados ao SUS [Internet]. 2017. Available on: http://conitec.gov.br/doismedicamentos-para-tratamento-de-hpv-sao-incorporados-ao-sus. Accessed 2 Sept 2020.

9. Protocolo Clínico e Diretrizes Terapêuticas para Atenção Integral às Pessoas com Infecções Sexualmente Transmissíveis (IST) [Internet]. Departamento de Vigilância, Prevenção e Controle das IST, HIV/Aids e Hepatites Virais. Available on: http://www.aids.gov.br/pt-br/pub/2015/protocolo-clinico-ediretrizes-terapeuticas-para-atencao-integral-pessoas-com-infeccoes. Accessed 2 Sept 2020

10. Didelot-Rousseau M-N, Nagot N, Costes-Martineau V, Vallès X, Ouedraogo A, Konate I, et al. Human papillomavirus genotype distribution and cervical squamous intraepithelial lesions among high-risk women with and without HIV-1 infection in Burkina Faso. Br J Cancer. 2006;95(3):355-62.

11. Mohammed $H$, Blomquist $P$, Ogaz $D$, Duffell $S$, Furegato $M$, Checchi $M$, et al. 100 years of STIs in the UK: a review of national surveillance data. Sex Transm Infect. 2018;94(8):553-8.

12. Hasanzadeh M, Rejali M, Mehramiz M, Akbari M, Seresht LM, Yazdandoost Y, et al. The interaction of high and low-risk human papillomavirus genotypes increases the risk of developing genital warts: a population-based cohort study. J Cell Biochem. 2019;120(8):12870-4.

13. Hernandez-Suarez G, Pineros M, Vargas JC, Orjuela L, Hernandez F, Peroza C, et al. Human papillomavirus genotypes in genital warts in Latin America: a cross-sectional study in Bogota, Colombia. Int J STD AIDS. 2013;24(7):567-72.

14. da Silva RJC, Sudenga SL, Sichero L, Baggio ML, Galan L, Cintra R, et al. HPVrelated external genital lesions among men residing in Brazil. Braz J Infect Dis. 2017:21(4):376-85

15. Ingles DJ, Pierce Campbell CM, Messina JA, Stoler MH, Lin H-Y, Fulp WJ, et al. Human papillomavirus virus (HPV) genotype- and age-specific analyses of external genital lesions among men in the HPV infection in men (HIM) study. J Infect Dis. 2015;211(7):1060-7.

16. Pierce Campbell CM, Gheit T, Tommasino M, Lin H-Y, Torres BN, Messina JL, et al. Cutaneous beta human papillomaviruses and the development of male external genital lesions: a case-control study nested within the HIM study. Virology. 2016:497:314-22.

17. Wendland EM, Horvath JDC, Kops NL, Bessel M, Caierão J, Hohenberger GF, et al. Sexual behavior across the transition to adulthood and sexually transmitted infections: findings from the national survey of human papillomavirus prevalence (POP-Brazil). Medicine (Baltimore). 2018;97(33):e11758.

18. Wendland EM, Villa LL, Unger ER, Domingues CM, Benzaken AS. Prevalence of HPV infection among sexually active adolescents and young adults in Brazil: the POP-Brazil study. Sci Rep. 2020;10(1):1-10.

19. Onyekwuluje JM, Steinau M, Swan DC, Unger ER. A real-time PCR assay for HPV52 detection and viral load quantification. Clin Lab. 2012;58(1-2):61-6. 
20. de Lima S, de Carvalho ML, Vasconcelos AGG. Proposal for a hierarchical framework applied to investigation of risk factors for neonatal mortality. Cad Saude Publica. 2008;24(8):1910-6.

21. Zhu C, Wang Y, Mao W, Zhang H, Ma J. Prevalence and distribution of HPV types in genital warts in Xi'an, China: a prospective study. BMJ Open. 2019; 9(5):e023897.

22. Guerra FM, Rosella LC, Dunn S, Wilson SE, Chen C, Deeks SL. Health service utilisation for anogenital warts in Ontario, Canada prior to the human papillomavirus (HPV) vaccine programme introduction: a retrospective longitudinal population-based study. BMJ Open. 2016;6(3):e009914.

23. Patel $H$, Wagner $M$, Singhal $P$, Kothari $S$. Systematic review of the incidence and prevalence of genital warts. BMC Infect Dis. 2013;13:39.

24. Khopkar US, Rajagopalan M, Chauhan AR, Kothari-Talwar S, Singhal PK, Yee $K$, et al. Prevalence and burden related to genital warts in India. Viral Immunol. 2018;31(5):346-51.

25. Lazcano-Ponce E, Sudenga SL, Torres BN, Stoler M, León-Maldonado L, Allen-Leigh $\mathrm{B}$, et al. Incidence of external genital lesions related to human papillomavirus among Mexican men. A cohort study. Salud Publica Mex. 2018;60(6):633-44.

26. Sudenga SL, Torres BN, Fulp WJ, Silva R, Villa LL, Lazcano-Ponce E, et al. Country-specific HPV-related genital disease among men residing in Brazil, Mexico, and the United States: the HIM study. Int J Cancer. 2017;140(2):33745 .

27. Rodrigues LLS, Hardick J, Nicol AF, Morgado MG, Martinelli KG, de Paula VS, et al. Sexually transmitted infections among HIV-infected and HIVuninfected women in the Tapajós region, Amazon, Brazil: self-collected vs. clinician-collected samples. PLoS One. 2019;14(4):e0215001.

28. Kim H-S, Kim TJ, Lee I-H, Hong SR. Associations between sexually transmitted infections, high-risk human papillomavirus infection, and abnormal cervical pap smear results in OB/GYN outpatients. J Gynecol Oncol. 2016;27(5):e49.

29. Bellaminutti S, Seraceni S, Seta FD, Gheit T, Tommasino M, Comar M. HPV and chlamydia trachomatis co-detection in young asymptomatic women from high incidence area for cervical cancer. J Med Virol. 2014;86(11):19205.

30. Schabath MB, Thompson ZJ, Egan KM, Torres BN, Nguyen A, Papenfuss MR, et al. Alcohol consumption and prevalence of human papillomavirus (HPV) infection among US men in the HPV in men (HIM) study. Sex Transm Infect. 2015;91(1):61-7.

31. Velazquez-Hernandez N, Sanchez-Anguiano LF, Guerra-Infante FM, AguilarDuran M, Perez-Alamos AR, Estrada-Martinez S, et al. Human papillomavirus infection in female sex workers: a case control study. J Clin Med Res. 2019; 11(3):196-201.

32. Min K-J, Lee J-K, Lee S, Kim MK. Alcohol consumption and viral load are synergistically associated with CIN1. PLoS One. 2013;8(8):e72142.

33. Nilyanimit P, Chansaenroj J, Srisomboon J, Rodrangnok W, Rajakom N, Daengsaard $E$, et al. Human papillomavirus in Thai women and men with Anogenital warts. Intervirology. 2018;61(5):223-9.

34. Ozaydin-Yavuz G, Bilgili SG, Guducuoglu H, Yavuz IH, Elibuyuk-Aksac S, Karadag AS. Determinants of high-risk human papillomavirus infection in anogenital warts. Postepy Dermatol Alergol. 2019;36(1):76-81.

35. Luo Z-Y, Chen Q, Yang H, Lin M, Chen C-Y, Yang C, et al. The prevalence and genotype of human papillomavirus from patients with genital warts in eastern Guangdong Province. Asian Pac J Cancer Prev APJCP. 2015;16(14): 5675-9.

36. Cremin S, Menton JF, Canier L, Horgan M, Fanning LJ. The prevalence and genotype of human papillomavirus on cervical samples from an Irish female population with external genital warts. Hum Vaccines Immunother. 2012; 8(7):916-20.

37. Arroyo Mühr LS, Bzhalava D, Lagheden C, Eklund C, Johansson H, Forslund $\mathrm{O}$, et al. Does human papillomavirus-negative condylomata exist? Virology. 2015;485:283-8

38. Crosbie EJ, Einstein MH, Franceschi S, Kitchener HC. Human papillomavirus and cervical cancer. Lancet. 2013;382(9895):889-99.

39. Bhatia N, Lynde C, Vender R, Bourcier M. Understanding genital warts: epidemiology, pathogenesis, and burden of disease of human papillomavirus. J Cutan Med Surg. 2013;17(Suppl 2):S47-54

\section{Publisher's Note}

Springer Nature remains neutral with regard to jurisdictional claims in published maps and institutional affiliations.

\section{Ready to submit your research? Choose BMC and benefit from:}

- fast, convenient online submission

- thorough peer review by experienced researchers in your field

- rapid publication on acceptance

- support for research data, including large and complex data types

- gold Open Access which fosters wider collaboration and increased citations

- maximum visibility for your research: over $100 \mathrm{M}$ website views per year

At $\mathrm{BMC}$, research is always in progress.

Learn more biomedcentral.com/submissions 